\title{
Acquisition of the internal and external constraints of variable schwa deletion by French immersion students
}

\author{
DORIN URITESCU, RAYMOND MOUGEON, KATHERINE REHNER, \\ AND TERRY NADASDI
}

\begin{abstract}
This article is one among a series of studies on the acquisition of patterns of linguistic variation observable in the speech of native speakers of Canadian French by French immersion (FI) students. The present study is centred on deletion of the central vowel schwa, a widespread feature of casual spoken French. In this study, FI students are compared with same age native speakers of Ontario French. Our study has arrived at the following main findings: (i) FI students delete schwa much less frequently than do the speakers of Ontario French; (ii) FI students observe the same phonetic constraints that influence schwa deletion in native Ontario French; (iii) FI students do not observe the constraint of topic formality which is observable in native Ontario French; and (iv) FI students who have had extracurricular contacts with native speakers of French display higher rates of schwa deletion than the FI students who have not had such contacts.
\end{abstract}

\section{Introduction}

First language (L1) sociolinguistic research has demonstrated that native speakers' alternation between two or more linguistic elements (variants) expressing the same meaning is an integral part of spoken language competence (cf. Labov 1966, 1972). It affects all components of language (syntax, morphology, lexicon, etc.), is highly frequent in L1 discourse, and is constrained by both linguistic factors (e.g., factors pertaining to the linguistic context in which the variants are used) and extralinguistic factors (e.g., sex, social status or group identity, and register or style).

However, the bulk of research on second language (L2) acquisition has focused on aspects of the target language where native speakers display invariant linguistic usage (i.e., use only one linguistic element to convey a given notion). In contrast, recent research taking a sociolinguistic perspective on L2 acquisition has begun to focus on aspects of the target language where native speak- 
ers display sociolinguistic variation. This type of research has investigated the learning of sociolinguistic variation in French (e.g., Dewaele 1999; Dewaele and Regan 2001; Knaus and Nadasdi 2001; Mougeon and Rehner 2001; Nadasdi and McKinnie 2003; Regan 1996; Rehner, Mougeon, and Nadasdi 2003; Sankoff et al. 1997) and a variety of other languages (e.g., Adamson and Regan 1991; Bayley and Preston 1996; Major to appear; Yamagata and Preston 1999). Thus, this new strand of research has started to fill a long-standing gap in the field of L2 acquisition studies.

As part of this new strand of research, the present article reports on an analysis of the phenomenon of schwa deletion in the spoken French of Ontario high school French immersion students who are learning French as a second language. The process of schwa deletion (e.g., la semaine versus la s'maine) dates back to the 15-16th century (Morin 1978) and is a sociolinguistic variable that has been much studied in L1 spoken European French, notably via corpusbased analysis (Hansen 1994, 2000; Malécot 1976; Péretz-Juillard 1977). Its frequency varies as a function of factors such as age and style and it is also highly constrained by the factor of phonetic context. However, the factor of social class does not seem to have much of an effect on this sociolinguistic variable (Hansen 2000). Interestingly, no prior corpus-based research of this phenomenon focused on spoken Quebec French has been carried out. However, two previous studies have looked at this sociolinguistic variable in Ontario French (Mougeon et al. 2002; Uritescu, Mougeon, and Handouleh, 2002). Both of these studies have underscored the effect of phonetic context on schwa deletion. The first study arrived at findings similar to those of Hansen (2000) in relation to social class stratification and the second study documented a much higher rate of schwa deletion in the context of a taped interview than in reading passages.

The present study of schwa deletion in the spoken French of Ontario high school French immersion students is part of a larger research project centered on the learning of spoken French sociolinguistic variation by French immersion students. This larger project seeks to answer the following questions:

1. Do the French immersion students under study use the same range of sociolinguistic variants as do native speakers of Quebec French?

2. Do the French immersion students use sociolinguistic variants with the same discursive frequency as do native speakers of Quebec French?

3. Is the French immersion students' use of sociolinguistic variants correlated with the same linguistic and stylistic constraints observable in spoken Quebec French?

4. What are the independent variables that influence the French immersion students' learning of sociolinguistic variation - for example, the treatment of sociolinguistic variation by French immersion teachers and the authors of French language arts materials used in French immersion programs, op- 
portunities to interact with L1 speakers, influence of the students' L1(s), influence of intrasystemic factors (e.g., markedness of the variants), and influence of the students' social characteristics (e.g., social standing, sex)?

To answer these questions, our research project takes as a starting point sociolinguistic variables that have been attested by numerous studies on the speech of French Quebeckers. These studies have been chosen because they are based on corpora that, like our French immersion student corpus, were collected via semiformal, semidirected taped interviews. This allows us to compare the immersion students with L1 speakers of Quebec French in the same communicative situation.

However, as we have pointed out above, as far as schwa deletion is concerned, there is no corpus-based research on this phenomenon in Quebec French. Therefore, for the present study we will use the spoken French of high school Francophone students from Ontario, also taped during semiformal, semidirected interviews, as the L1 benchmark, as we have done in Uritescu, Mougeon, and Handouleh (2002).

The purpose of the present paper is to push further the research undertaken by Uritescu, Mougeon, and Handouleh (2002) by: (1) focusing on two external factors that were not previously examined, namely social class and style as measured by the more subtle effect of topic formality as opposed to a contrast between speech and reading; (2) considering not only the phonetic contexts that were previously identified as most favorable to schwa deletion, but also those that are generally considered as unfavorable to such deletion; and (3) using larger samples of both L1 and L2 speakers of French.

\subsection{Previous studies of schwa deletion in L1 spoken French}

The sociolinguistic variable under study in the present paper can be defined as the presence or absence of schwa in nonfinal syllables. This focus on nonfinal syllables reflects the fact that, in final syllables, schwa is almost always deleted in Ontario French (Uritescu, Mougeon, and Handouleh 2002). By final syllables we mean syllables at the end of rhythmic groups (e.g., il vient tout de suite [sqit] 'he's coming right away') and at the end of group-medial words that, on an underlying level, do not contain a final schwa (e.g., il donne [don] des conseils 'he gives advice'). Since the deletion of schwa in such cases is categorical in Ontario French, it cannot be reconstructed by speakers.

Most studies on schwa in French have tried to identify the factors that influence its deletion or maintenance. The most well-known factor that has been hypothesized to promote the maintenance of schwa is the rule of three consonants in French (see recently Walter 1990; Picard 1991). According to this rule, a schwa cannot be deleted when the outcome of this deletion is a cluster of three (or more) consonants (e.g., vendredi $\rightarrow *$ vendr'di; mercredi $\rightarrow *$ mercr'di). 
Recent studies have also focused on the evolution of schwa. Some researchers suggest that schwa is undergoing a process of 'stabilization' (i.e., an increase in the number of words in which the retention of schwa is categorical or more and more frequent, especially in initial syllables - Fónagy 1989; Morin 1978; Walter 1988, 1990). Other researchers, based on their analyses of Parisian French corpora, have noted that young speakers delete schwa more frequently than do older speakers, suggesting that this vowel is not stabilizing, but undergoing a process of progressive deletion (Léon and Tennant 1988; Malécot 1976; Péretz-Juillard 1977). Finally, in a recent study on schwa deletion in Parisian French, Hansen (1994) compares the results of Péretz-Juillard (1977) with the results of her own corpus (gathered in 1989) and reaches the conclusion that schwa deletion is not on the increase, but in fact constitutes a stable sociolinguistic variable, in the Labovian sense of the term.

\subsection{Previous studies of schwa deletion in L2 spoken French}

Two previous studies have examined schwa deletion in the spoken French of L2 learners - Uritescu, Mougeon, and Handouleh (2002) in the speech of eight immersion students and Thomas (2002 and this issue) in that of 87 university level learners. Both studies found that the L2 learners delete schwa at levels below native norms, at least in those contexts where deletion is not categorical. In connection with this, both studies also found that the L2 learners follow the hierarchy of phonetic contexts that constrains schwa deletion in L1 speech. Thomas (2002) looked at a binary contextual opposition, while Uritescu, Mougeon, and Handouleh (2002) examined five contexts. Where these two studies differ is in documenting an influence of extracurricular exposure to French on the deletion of schwa. Thomas found that after eight months in an FSL program in a university in France the L2 learners had not changed their rate of schwa deletion in a significant way, whereas Uritescu, Mougeon, and Handouleh (2002) found that those immersion students who had had the opportunity of staying with a Francophone family displayed significantly higher rates of schwa deletion than the remaining students. The difference may reflect the fact that families provide a richer and more intense opportunity to learn the language than FSL programs where non-native speakers from the same language background are grouped together and interact frequently together. Finally, Uritescu, Mougeon, and Handouleh (2002) found that the immersion students displayed a somewhat higher level of schwa deletion in the context of a taped interview than they did in a reading passage.

\section{Methodology}

The taped semidirected interviews were carried out among 41 grade 9 and 12 French immersion students (adolescents of approximately 14 and 17 years of 
Table 1. Chief characteristics of the French immersion student subsample

\begin{tabular}{|c|c|c|c|c|c|c|}
\hline Grade & Sex & Social class & $\begin{array}{l}\text { Exposure to } \\
\text { TV and } \\
\text { radio } \\
\text { in French }\end{array}$ & $\begin{array}{l}\text { Time in } \\
\text { Francophone } \\
\text { environment }\end{array}$ & $\begin{array}{l}\text { Time with } \\
\text { Francophone } \\
\text { family }\end{array}$ & $\begin{array}{l}\text { Languages } \\
\text { spoken } \\
\text { at home }\end{array}$ \\
\hline $9=2$ & $\mathrm{~F}=7$ & Middle $=4$ & Never $=3$ & 0 hours $=3$ & 0 hours $=4$ & English $=5$ \\
\hline $12=6$ & $M=1$ & $\begin{array}{l}\text { Upper- } \\
\text { work=4 }\end{array}$ & Occasional $=5$ & $\begin{array}{l}1-20 \text { days }=2 \\
3 \text { weeks }+=3\end{array}$ & $\begin{array}{l}1-13 \text { days }=1 \\
2 \text { weeks }+=3\end{array}$ & $\begin{array}{l}\text { Romance }=2 \\
\text { Other }=1\end{array}$ \\
\hline
\end{tabular}

age). These interviews followed a set of questions that was modeled on those used for the grade 9 and $12 \mathrm{~L} 1$ speakers of Ontario French. For the present study, we are using a subsample of eight French immersion students and another of nine L1 speakers of Ontario French. It should be pointed out that the sample of eight immersion students is not identical to that used by Uritescu, Mougeon, and Handouleh (2002) so as to enable the possibility of examining the effect of social class and sex with a more evenly distributed subsample.

\subsection{The immersion speaker sample}

The French immersion student sample was collected in a program characterized by $50 \%$ French-medium instruction in grades 5 to 8 , followed by $20 \%$ in high school. The immersion program in question is housed in regular Englishlanguage high schools where the great majority of the administrative, teaching, and maintenance staff, and also students, are not French-speaking. In other words, in the school setting, the immersion students rely almost exclusively on their French-medium classes to use and be exposed to French.

The characteristics of the eight immersion students under study here are displayed in Table 1. As can be seen, the students have had differing degrees of exposure to French outside the school. Further, they come from homes where neither parent speaks French, but where both parents are by no means all unilingual Anglophones.

\subsection{The L1 speaker sample}

In the province of Ontario, nearly half a million people speak French as their L1. The nine adolescent speakers of French from Ontario under study here are from a French-medium high school in North Bay, Ontario, a city where Francophones represent only $18 \%$ of the population. The Ontario Government guarantees the right to French-medium schooling for Ontario children of Francophone parents. Prior to attending their French medium high school, the nine Franco-Ontarian students under study here also attended a French-medium el- 
Table 2. Chief characteristics of the Ontario Francophone student subsample

\begin{tabular}{lll}
\hline Grade & Sex & Social class \\
\hline $9=3$ & $\mathrm{~F}=3$ & Middle $=2$ \\
$12=6$ & $\mathrm{M}=6$ & Low-mid=3 \\
& & Working=4 \\
\hline
\end{tabular}

ementary school. These nine students are each from homes where at least one parent speaks French as a mother tongue.

\section{Previous results for the immersion corpus}

Before turning to the results of the current study, let us highlight some of the findings arrived at in our larger project examining the learning of sociolinguistic variation by Ontario French immersion students (see Mougeon, Nadasdi, and Rehner 2002; Rehner, Mougeon, and Nadasdi 2003).

- The French immersion students use mildly marked variants at levels considerably below those of L1 speakers.

Mildly marked variants are features that do not conform to Standard French and that are typical of the informal register, but that may also be used in formal situations. As such, they are not as sharply socially stratified or stigmatized as vernacular variants and they occur with considerable frequency in the speech of L1 speakers, even in the context of a semiformal interview. Schwa deletion, which is the focus of the present study, is an example of a mildly marked variant, since it is both frequent in spoken L1 French, even in the context of recorded speech, and it is not constrained by social class.

- The immersion students display a partial mastery of the linguistic constraints on variation observed by L1 speakers.

The use of the term 'partial' here reflects the fact that we have found that the immersion students master all the linguistic constraints for some sociolinguistic variables, only a subset of such constraints for other variables, and none of the linguistic constraints of yet other variables.

o It is unclear to what extent the immersion students are able to style shift.

To date, we have examined the effect of style shifting in connection with only three variables. In two instances the students did not display the ability to style shift and in the third case that was, as we have pointed out, focused on schwa, the students displayed some measure of style shifting ability (interview versus reading passage).

- The female and/or middle class immersion students display a stronger preference for formal standard variants than do the male and/or upper-working class students. 
This well-attested trend in our research (Mougeon, Nadasdi, and Rehner 2002) reflects the immersion students' sensibility to the treatment of specific variants in their educational input (e.g., correction on the part of the teachers, categorical avoidance of certain variants in the teaching materials). We attribute this finding to a carry-over on the part of the female and/middle class students of a trend to favor standard variants as they can be assumed to do in their L1 (see Labov 1990, among others, for a discussion of this widespread tendency).

- The immersion students with greater extracurricular exposure to L1 French use mildly marked variants more often than do the remaining students.

This finding is not surprising since, as we have pointed out, mildly marked variants are quite frequent in L1 speech and, hence, those students who are exposed to this speech will have an edge in the learning of such variants.

\subsection{Hypotheses for the immersion students' deletion of schwa}

Given the above summary of research results on the learning of sociolinguistic variation by the 41 French immersion students from the Mougeon and Nadasdi corpus and bearing in mind the results of Uritescu, Mougeon, and Handouleh's (2002) previous study of schwa deletion by a subset of these same French immersion students, we can make the following hypotheses regarding the deletion of schwa by the eight French immersion students under study:

1 The immersion students will use the mildly marked variant of schwa deletion less often than will the L1 speakers of Ontario French.

2 The immersion students will observe the same overall hierarchy of phonetic constraints as do the L1 speakers of Ontario French.

3 Whether the immersion students will display the ability to style shift in relation to schwa deletion is an open question in the present study because we have opted to use a more subtle measure of style than that used in the Uritescu, Mougeon, and Handouleh (2002) study. Instead of relying on an opposition between the interview and a reading passage, we are measuring the effect of topic formality.

4 The female and/or middle class immersion students will delete schwa less often than will the male and/or upper working class students.

5 The immersion students with greater extracurricular exposure to L1 French will delete schwa more often than will the remaining students.

\section{Results}

Firstly, as we had hypothesized, there is a marked difference in the frequency of use of the mildly marked variant of schwa deletion in the speech of the immersion students and in that of the L1 speakers. The overall frequency of schwa deletion for the immersion students is $21 \%$ (see Table 4), while for the L1 speakers it is $68 \%$ (see Table 3). 
To assess the effect of the various linguistic and extralinguistic factors examined, we calculated rates of schwa deletion as a function of these factors and used GoldVarb to determine statistically significant differences and to identify the factors correlated with schwa deletion.

\subsection{Influence of phonetic context}

The linguistic factors taken into account are the phonetic contexts in which schwa undergoes variable deletion. This list, provided below, includes contexts that have been examined in previous studies, that is contexts A-F, considered to be favorable to schwa deletion since schwa is preceded by only one consonant, and contexts that have not been examined in previous studies, that is contexts G-L, considered to be resistant to schwa deletion because of the presence of at least one phonetic factor that diminishes the probability of schwa being deleted (e.g., more than one preceding consonant, a schwa preceding or following another schwa). Concerning context $\mathrm{F}$, we should point out that, even though schwa occurs in wordfinal position, it is present in the underlying phonological representation and, hence, it is deletable. Finally, in sequences where two schwas occur successively only one can be deleted. In these sequences we did not measure the frequency of deletion of schwa in one context as opposed to the other (e.g., contexts $\mathrm{G}$ and $\mathrm{H}$ ).

\section{Phonetic contexts of schwa deletion}

A. Word initial syllable following a pause or vowel not followed by another schwa: ça va v(e)nir 'it will come'

B. Monosyllable at the beginning of a rhythmic group not followed by a foreign word or a word beginning with an aspirated ' $h$ ' nor by a syllable containing a schwa: $j(e)$ sais pas 'I don't know'

C. Sequence of monosyllables not following a consonant or another schwa: $j(e)$ me baignais beaucoup/je m(e) baignais beaucoup 'I used to go swimming a lot'

D. Monosyllable in group-medial position and following a vowel: beaucoup $d(e)$ monde 'A lot of people'

E. Word-medial following a single consonant: je gagne un peu d'argent maint(e)nant 'I'm making a little money now'

F. Forms such as quelque pronounced [kek(ə)]: j'ai lu quelqu(e)s livres 'I read a few books'

G. Word initial syllable:

following more than one consonant: sept s(e)maines 'seven weeks' following a monosyllable including a schwa: il faut le d(e)viner 'you must guess'

followed by a syllable containing another schwa: $r(e)$ venir 'to come back' 
H. Monosyllable at the beginning of a rhythmic group followed by a: foreign word: l(e) curling 'curling'

word beginning with an aspirated ' $h$ ': $l(e)$ hibou 'the owl'

syllable containing a schwa: j(e) reviens 'I am coming back'

I. Sequence of monosyllables following:

a consonant: hier j(e) me suis réveillé tard / hier je m(e) suis réveillé tard 'yesterday I woke up late'

another schwa: qu'est-ce que j(e) me rappelle? / qu'est-ce que je m(e) rappelle? 'what do I remember?'

J. Group-medial monosyllable following a consonant: je pense qu(e) c'est difficile 'I think it is difficult'

$\mathrm{K}$. Word-medial following more than one consonant: exact(e)ment! 'exactly!'

L. Phrase final que preceded by a consonant: qu'est-ce qu(e) tu fais? 'What are you doing?'; parce que c'est bon 'Because it is good'

In order to determine to what extent the immersion students respect the linguistic constraints of schwa deletion observed by L1 speakers, we must first examine the speech of the nine Franco-Ontarian adolescents who are the L1 benchmark for the present study.

As can be seen in Table 3, there is a considerable range of rates of deletion and associated factor effects (from $88 \%$ deletion to $25 \%$ ) as a function of phonetic context. The average deletion rate is $68 \%$. For contexts $\mathrm{A}, \mathrm{B}$, and $\mathrm{E}$, the three contexts considered by Hansen $(1994,2000),{ }^{1}$ the Franco-Ontarian adolescents delete schwa $76 \%$ of the time on average compared to Hansen's native speakers of Parisian French who do so $72 \%$ of the time. Note also that for those contexts that were not included in previous sociolinguistic research because they were thought to be resistant to schwa deletion, namely contexts $\mathrm{G}-\mathrm{L}$, we find a range of deletion between 25 and $87 \%$. In fact, based on the factor effects, context $\mathrm{K}$ turns out to be more favorable to schwa deletion than to schwa maintenance.

Table 3 also shows that there are two natural breaks in the range of deletion rates. There are contexts that are quite favorable to schwa deletion (i.e., C, F, E and $\mathrm{K}$ ) and those that are either somewhat favorable to schwa deletion (i.e., B, $\mathrm{D}, \mathrm{A}, \mathrm{G}$ and I) or somewhat unfavorable to schwa deletion (i.e., $\mathrm{L}, \mathrm{H}$ and $\mathrm{J}$ ).

Let us turn now to results for the immersion students. Table 4 shows that while there is also a wide range of rates of deletion and associated factor effects in the immersion students' speech, three phonetic contexts are, according to the factor effects, highly favorable to schwa deletion, namely $\mathrm{K}$, E, and C. These three contexts are also those that are most favorable in the FrancoOntarian data. Note, however, that the order of these three contexts is not the same as for the L1 speakers and, notably, that context $\mathrm{K}$ is the most favorable context in immersion speech. Finally, the second most favorable context for the Franco-Ontarian speakers, namely context $\mathrm{F}$ that corresponds to quelque, 
Table 3. Schwa deletion by Franco-Ontarian students as a function of phonetic context

\begin{tabular}{lccccc}
\hline Context & $\begin{array}{c}\text { Total } \\
\text { occurrences } \\
(\mathrm{n})\end{array}$ & $\begin{array}{c}\text { Schwas } \\
\text { maintained } \\
(\mathrm{n})\end{array}$ & $\begin{array}{c}\text { Schwas } \\
\text { deleted } \\
(\mathrm{n})\end{array}$ & $\begin{array}{c}\text { Schwas } \\
\text { deleted } \\
(\%)\end{array}$ & $\begin{array}{c}\text { Factor effect } \\
\text { for schwa } \\
\text { deletion }\end{array}$ \\
\hline C. & 51 & 6 & 45 & 88 & 0.76 \\
F. & 48 & 6 & 42 & 88 & 0.75 \\
E. & 137 & 17 & 120 & 88 & 0.75 \\
K. & 82 & 11 & 71 & 87 & 0.74 \\
B. & 614 & 150 & 464 & 76 & 0.57 \\
D. & 535 & 136 & 399 & 75 & 0.56 \\
A. & 189 & 61 & 128 & 68 & 0.48 \\
G. & 76 & 28 & 48 & 63 & 0.43 \\
I. & 22 & 9 & 13 & 59 & 0.39 \\
L. & 47 & 29 & 18 & 38 & 0.21 \\
H. & 40 & 27 & 13 & 33 & 0.17 \\
J. & 276 & 208 & 68 & 25 & 0.12 \\
& & & & & Input 0.69 \\
Total & 2117 & 688 & 1429 & 68 & Sig. $0.00^{\text {a }}$ \\
\hline
\end{tabular}

a The input value is a measure of the overall probability of schwa deletion. With the GoldVarb regression analysis, differences in probability higher than 0.05 are considered significant.

almost always pronounced in $\mathrm{L} 1$ French as $/ \mathrm{k} E \mathrm{k} /$ is a context that is entirely impervious to schwa deletion in the speech of the immersion students.

If we look now at the set of contexts that are somewhat favorable to schwa deletion in native speech, namely contexts B, D, A, G, and I, we see that these are also somewhat favorable in the speech of the immersion students. The only exception is context I that is in the wrong cluster and seems to have been replaced by context L in the hierarchy. Finally, there is also a general match between the immersion students and the Franco-Ontarians in relation to the contexts that are clearly unfavorable to schwa deletion.

Having said this, it is interesting that the rates of deletion expressed in percentages reveal that outside of contexts $\mathrm{K}$ and $\mathrm{E}$, frequency of schwa deletion in the speech of the immersion students drops drastically. In fact, in six of the phonetic contexts under study (i.e., G, L, D, I, J, and H) the percentage of schwa deletion for the immersion students drops below $10 \%$, whereas in these same contexts the Franco-Ontarian speakers exhibit a range of deletion rates from $25 \%$ to $75 \%$. 
Table 4. Schwa deletion by immersion students as a function of phonetic context

\begin{tabular}{lcrrrrr}
\hline Context & $\begin{array}{c}\text { Order for } \\
\text { native } \\
\text { speakers }\end{array}$ & $\begin{array}{c}\text { Total } \\
\text { occurrences } \\
(\mathrm{n})\end{array}$ & $\begin{array}{c}\text { Schwas } \\
\text { maintained } \\
(\mathrm{n})\end{array}$ & $\begin{array}{c}\text { Schwas } \\
\text { deleted } \\
(\mathrm{n})\end{array}$ & $\begin{array}{c}\text { Schwas } \\
\text { deleted } \\
(\%)\end{array}$ & $\begin{array}{c}\text { Factor effect } \\
\text { for schwa } \\
\text { deletion }\end{array}$ \\
\hline K. & C. & 238 & 47 & 191 & 80 & 0.96 \\
E. & F. & 195 & 50 & 145 & 74 & 0.95 \\
C. & E. & 185 & 123 & 62 & 34 & 0.76 \\
A. & K. & 129 & 108 & 21 & 16 & 0.55 \\
B. & B. & 670 & 598 & 72 & 11 & 0.43 \\
G. & D. & 87 & 79 & 8 & 9 & 0.39 \\
L. & A. & 135 & 124 & 11 & 8 & 0.36 \\
D. & G. & 690 & 652 & 38 & 6 & 0.27 \\
I. & I. & 44 & 42 & 2 & 5 & 0.23 \\
J. & L. & 316 & 309 & 7 & 2 & 0.12 \\
H. & H. & 18 & 18 & 0 & 0 & - \\
F. & J. & 142 & 142 & 0 & 0 & - \\
& & & & & & Input 0.13 \\
Total & & 2689 & 2132 & 557 & 21 & Sig. 0.00 \\
\hline
\end{tabular}

\subsection{Extralinguistic factors}

The data on schwa deletion have been analysed as a function of three extralinguistic factors, namely sex and social class, extracurricular exposure to French and topic formality. Concerning this latter factor, we parsed the interview transcripts into stretches of speech associated with eight different topics that have been regrouped under a formal versus informal distinction.

Table 5 displays the results of the GoldVarb analysis on the impact of extralinguistic factors on the immersion students' deletion of schwa. As can be seen, as far as style is concerned, the immersion students do not display a pattern of style shifting, since this factor was not selected by GoldVarb. Furthermore, the percentage frequency of schwa deletion goes in the wrong direction (i.e., more frequent in the students' speech on formal topics than in their speech on informal topics). This finding is in contrast with that for the L1 speakers who delete schwa more often in informal topics than in formal ones (73\% versus $65 \%$, respectively), the difference having been established as significant by GoldVarb (see Table 6).

Concerning social class, this factor was not selected as significant by GoldVarb (see Table 5). The fact that sex was deemed to be significant should be taken with considerable caution, since in our sample of immersion students the two gender groups are not equally represented. Furthermore, it is interesting that in the speech of the Franco-Ontarian students, neither sex nor social class 
Dorin Uritescu et al.

Table 5. GoldVarb analysis of the effect of extralinguistic factors on schwa deletion by French immersion students

\begin{tabular}{|c|c|c|c|c|c|}
\hline Factors & $\begin{array}{l}\text { Schwa } \\
\text { deletion } \\
\text { (n) }\end{array}$ & $\begin{array}{c}\text { Schwa } \\
\text { deletion } \\
(\%)\end{array}$ & $\begin{array}{l}\text { Schwa } \\
\text { use } \\
\text { (n) }\end{array}$ & $\begin{array}{l}\text { Schwa } \\
\text { use } \\
(\%)\end{array}$ & $\begin{array}{c}\text { Effect } \\
\text { for schwa } \\
\text { deletion }\end{array}$ \\
\hline \multicolumn{6}{|l|}{ Style } \\
\hline Formal & 335 & 22 & 1204 & 78 & \multirow[t]{2}{*}{ n.s. } \\
\hline Informal & 222 & 19 & 946 & 81 & \\
\hline \multicolumn{6}{|l|}{ Sex } \\
\hline Female & 488 & 22 & 1729 & 78 & 0.53 \\
\hline Male & 69 & 14 & 421 & 86 & 0.35 \\
\hline \multicolumn{6}{|l|}{ Social Class } \\
\hline Middle & 321 & 17 & 1526 & 83 & \multirow[t]{2}{*}{ n.s. } \\
\hline Upper-working & 236 & 27 & 624 & 73 & \\
\hline \multicolumn{6}{|l|}{ French Media } \\
\hline Never & 274 & 18 & 1243 & 82 & 0.47 \\
\hline Occasionally & 283 & 24 & 907 & 76 & 0.53 \\
\hline \multicolumn{6}{|l|}{ French family } \\
\hline Nil & 227 & 16 & 1211 & 84 & 0.42 \\
\hline 1 week + & 330 & 26 & 939 & 74 & 0.58 \\
\hline \multicolumn{6}{|l|}{ French environment } \\
\hline Nil & 159 & 16 & 834 & 84 & n.s. \\
\hline 1 week + & 398 & 23 & 1316 & 77 & \\
\hline Total & 557 & 21 & 2150 & 79 & $\begin{array}{c}\text { Input } 0.19 \\
\text { Sig. } 0.03\end{array}$ \\
\hline
\end{tabular}

exerts a significant effect on schwa deletion (see Table 6). This suggests that schwa deletion in this variety of French is not strongly marked socially.

Finally, as we had predicted, extracurricular exposure to L1 French exerts a positive influence on the immersion students' deletion of schwa. This effect was found with the factors of stays in a Francophone family and exposure to French media. The factor of stay in a Francophone environment was not selected. However, the percentage frequencies differ in the expected direction.

\section{Discussion}

Let us turn now to a discussion of the results of the present study. First, we have seen that, as expected, the immersion students employ the mildly marked variant of schwa deletion much less often than do the L1 speakers, $21 \%$ versus $68 \%$. While this clearly reveals a gap between the L2 learners and the L1 norms, it is not as substantial as the one found in our previous study of /1/ 
Table 6. GoldVarb analysis of the effect of extralinguistic factors on schwa deletion by Franco-Ontarian students

\begin{tabular}{lccccc}
\hline Factors & $\begin{array}{c}\text { Schwa } \\
\text { deletion } \\
(\mathrm{n})\end{array}$ & $\begin{array}{c}\text { Schwa } \\
\text { deletion } \\
(\%)\end{array}$ & $\begin{array}{c}\text { Schwa } \\
\text { use } \\
(\mathrm{n})\end{array}$ & $\begin{array}{c}\text { Schwa } \\
\text { use } \\
(\%)\end{array}$ & $\begin{array}{c}\text { Effect } \\
\text { for schwa } \\
\text { deletion }\end{array}$ \\
\hline $\begin{array}{l}\text { Topic formality } \\
\quad \text { Formal }\end{array}$ & 984 & 65 & 520 & 35 & 0.47 \\
$\quad$ Informal & 445 & 73 & 168 & 27 & 0.55 \\
Sex & & & & & \\
$\quad$ Female & 428 & 73 & 156 & 27 & n.s. \\
$\quad$ Male & 1001 & 65 & 532 & 35 & \\
$\begin{array}{l}\text { Social Class } \\
\quad \text { Middle }\end{array}$ & 646 & 67 & 325 & 33 & \\
$\quad$ Lower-middle & 511 & 65 & 270 & 35 & n.s. \\
$\quad$ Working & 272 & 75 & 93 & 25 & Input 0.70 \\
$\quad$ Total & 1429 & 68 & 688 & 32 & Sig. 0.01 \\
\hline
\end{tabular}

deletion in subject pronouns in the speech of these same students where they almost never (2\%) delete a sound that is almost categorically (98\%) deleted in L1 French (Nadasdi et al. 2001). One explanation for the difference may be that schwa deletion is a "natural" phonological process, whereas /1/ deletion is a morphophonemic process (i.e., it occurs only in specific grammatical morphemes) and, hence, needs to be entirely acquired.

Second, we have seen that, as hypothesized, the immersion students observe, by and large, the same phonetic constraints observed by L1 speakers. However these findings may partly reflect the fact that some of these constraints are natural and universal (see Donegan and Stampe 1979; Dressler 1985; and Donegan 1993 on natural phonology). One context, however, was the locus of a hierarchical mismatch between the immersion students and the L1 speakers, namely context $\mathrm{K}$ where a word-medial schwa follows more than one consonant. One possible explanation for this finding is that several of the words that include this context have an English cognate that does not contain a schwa (e.g., gouvernement and government; appartement and apartment). ${ }^{2}$ Finally, another difference related to phonetic context was the absence of schwa deletion in quelque - context F - which, in contrast, is almost categorical in L1 French where its pronunciation as $/ \mathrm{k} k \mathrm{k} / \mathrm{has}$ been lexicalized. A possible explanation for this is that the students' teachers may avoid this informal pronunciation in the classroom. 
Finally, as we have seen, the present study has underscored, as hypothesized, the favorable effect of exposure to L1 spoken French outside the school context on the immersion students' acquisition of a mildly marked informal variant. The fact that this variant's social salience is very low and its discursive frequency very high likely explains the beneficial effect of extracurricular interactions with L1 speakers. Further, we have seen that the immersion students do not attach a clear social value to schwa deletion. This finding is perhaps not too surprising since schwa deletion seems to be a case of a mildly marked variant that exhibits little or no correlation with sex and social class in L1 French. Therefore, one can surmise that teachers in the immersion context do not pay much attention to the variant of schwa deletion (e.g., they do not correct the students who delete this vowel and they do not, by and large, refrain from deleting schwa themselves). ${ }^{3}$ The finding that the immersion students did not display a pattern of style shifting as a function of topic, while the L1 speakers did, is perhaps not overly surprising given that, in Uritescu, Mougeon, and Handouleh (2002), we found that they displayed only a modest measure of style shifting ability when we contrasted their interview speech with their reading passages. Thus, with the much more subtle measure of style shifting examined in the current study, the immersion students clearly have 'a ways to go' before they display a native-like pattern.

\author{
York University \\ $<$ dorinu@yorku.ca> \\ $<$ rmougeon@yorku.ca> \\ $<$ krehner@yorku.ca> \\ University of Alberta \\ <terry.nadasdi@ualberta.ca>
}

\title{
Notes
}

1. Hansen $(1994,2000)$ also considered context D, but collapsed it with context B.

2. According to Hansen (personal communication December 2003), in this same context, speakers of Parisian French show a high level of schwa retention. This raises the possibility that the high level of schwa deletion in this particular context on the part of the Franco-Ontarian students may also be partly a result of the process of phonetic convergence mentioned above.

3. A possible exception to this, as we have pointed out, is the informal pronunciation of quelque.

\section{References}

Adamson, Doug and Vera Regan (1991). The acquisition of community speech norms by Asian immigrants learning English as a second language: A preliminary study. Studies in Second Language Acquisition 13 (1): 1-22. 
Bayley, Robert and Dennis Preston (eds.) (1996). Second Language Acquisition and Linguistic Variation. Philadelphia: Benjamins.

Dewaele, Jean-Marc (1999). Word order variation in French interrogatives. ITL Review of Applied Linguistics 125/126: 161-180.

Dewaele, Jean-Marc and Vera Regan (2001). The use of colloquial words in advanced French interlanguage. In EUROSLA Yearbook 1, Susan Foster-Cohen and Anna Nizegorodcew (eds.), 51-78. Amsterdam and Philadelphia: Benjamins.

Donegan, Patricia (1993). On the phonetic basis of phonological change. In Historical Linguistics: Problems and Perspectives, Charles Jones, (ed.), 98-133. London and New York: Longman.

Donegan, Patricia and David Stampe. (1979). The study of natural phonology. In Current Approaches to Phonological Theory, Daniel A. Dinnsen (ed.), 126-174. Bloomington: Indiana University Press.

Dressler, Wolfgang U. (1985). Morphonology: The Dynamics of Derivation. Ann Arbor: Karoma Press.

Fónagy, Ivan (1989). Le français change de visage? Revue Romane 24: 225-254.

Hansen, Anita Berit (1994). Étude du E caduc - stabilisation en cours et variations lexicales. Journal of French Studies 4: 25-54.

- (2000). Le E caduc interconsonantique en tant que variable sociolinguistique: une étude en région parisienne. LINX 42: 45-58.

Knaus, Valerie and Terry Nadasdi (2001). Être ou ne pas être en immersion. The Canadian Modern Language Review 58 (2): 287-306.

Labov, William (1966). The Social Stratification of English in New York City. Washington, DC: Center for Applied Linguistics.

- (1972). Sociolinguistic Patterns. Philadelphia: University of Pennsylvania Press.

- (1990). The intersection of gender and social class in the course of linguistic change. Language Variation and Change 11: 205-254.

Léon, Pierre and Jeff Tennant (1988). Observations sur la variation morphonologique et phonématique dans Apostrophes. Information Communication - Toronto Working Papers 9: 20-47.

Major, Roy (to appear). Gender and stylistic variation in second language phonology. Language Variation and Change.

Malécot, André (1976). The effect of linguistic and paralinguistic variables on the elision of the French mute-e. Phonetica 33: 93-112.

Morin, Yves-Charles (1978). The status of mute 'e'. Studies in French Linguistics 1/2: 79-140.

Mougeon, Raymond and Katherine Rehner (2001). Variation in the spoken French of Ontario French immersion students: The case of juste vs seulement vs rien que. Modern Language Journal 85: 398-415.

Mougeon, Raymond, Terry Nadasdi, and Katherine Rehner (2002). État de la recherche sur l'appropriation de la variation par les apprenants avancés du FL2 ou FLE. In L'acquisition de la Variation par les Apprenants du Français Langue Seconde, Jean-Marc Dewaele and Raymond Mougeon (eds.), Special issue of Acquisition et Interaction en Langue Étrangère 17: $7-50$.

Mougeon, Raymond, Terry Nadasdi, Katherine Rehner, and Dorin Uritescu (2002). The sharing of constraints in minority speech communities. Paper read at NWAV 31, Stanford University, 10-13 October.

Nadasdi, Terry and Meghan McKinnie (2003). Living and working in immersion French. Journal of French Language Studies 13 (1): 63-104.

Nadasdi, Terry, Dorin Uritescu, Raymond Mougeon, and Katherine Rehner (2001). A sociolinguistic analysis of phonetic variation in the spoken French of immersion students. Paper presented at the annual meeting of the Canadian Association of Applied Linguistics, Université Laval, 31 May-3 June.

Péretz-Juillard, Caroline (1977). Les voyelles orales à Paris dans la dynamique des âges et de la société. Thèse de $\mathrm{III}^{\mathrm{e}}$ cycle, Université de Paris V. 


\section{Dorin Uritescu et al.}

Picard, Marc (1991). La loi des trois consonnes et la chute du cheva en québécois. Revue québécoise de linguistique 20/2: 35-49.

Regan, Vera (1996). Variation in French interlanguage: A longitudinal study of sociolinguistic competence. In Second Language Acquisition and Linguistic Variation, Robert Bayley and Dennis Preston (eds.), 177-201. Philadelphia: Benjamins.

Rehner, Katherine, Raymond Mougeon, and Terry Nadasdi (2003). The learning of sociolinguistic variation by advanced FSL learners: The case of nous versus on in immersion French. Studies in Second Language Acquisition 25: 127-156.

Sankoff, Gillian, Pierrette Thibault, Naomi Nagy, Hélène Blondeau, Marie-Odile Fonollosa, and Lucie Gagnon (1997). Variation in the use of discourse markers in a language contact situation. Language Variation and Change 9 (2): 191-217.

Thomas, Alain (2002). La variation phonétique en français langue seconde au niveau universitaire avancé. In L'acquisition de la Variation par les Apprenants du Français Langue Seconde, Jean-Marc Dewaele and Raymond Mougeon (eds.), Special issue of Acquisition et Interaction en Langue Étrangère 17: 101-121.

Uritescu, Dorin, Raymond Mougeon, and Yassin Handouleh (2002). Le comportement du schwa dans le français parlé par les élèves des programmes d'immersion française. In La Linguistique Fonctionnelle au Tournant du Siècle. Actes du $24^{e}$ Colloque International de Linguistique Fonctionnelle, Claude Tatilon and Alain Baudot (eds.), 335-346. Toronto: Éditions du GREF.

Walter, Henriette (1988). Une voyelle de moins en moins muette. Liaison Alfonic 2: 11-14.

- (1990). Une voyelle qui ne veut pas mourir. In Variation and Change in French. Essays Presented to Rebecca Posner on the Occasion of her Sixtieth Birthday, John N. Green and Wendy Ayres-Bennett (eds.), 27-36. London and New York: Routledge.

Yamagata, Ayako and Dennis Preston (1999). Gemination in the Katakana spelling of English loan-words. Paper presented at NWAV 28, University of Toronto and York University, 15-17 October. 